\title{
PREDIKSI KUAT TEKAN PERVIOUS PAVING DENGAN CAMPURAN ABU SEKAM DENGAN MENGGUNAKAN PEMODELAN ARTIFICIAL NEURAL NETWORK (ANN)
}

\author{
Erna Suryani $^{(1)}$,Wahyu Naris Wari ${ }^{(2)}$ \\ 1,2 Jurusan Teknik Sipil, Politeknik Negeri Banyuwangi, Jl. Raya Jember, KM. 13, Banyuwangi 68461, \\ email: \\ erna@poliwangi.ac.id,naris@poliwangi.ac.id
}

\begin{abstract}
ABSTRAK
Pervious Paving (Paving Berpori) adalah material konstruksi yang terbuat dari semen, air, agregat dan bahan campuran lainnya. Paving berpori dapat diapilkasikan pada trotoar, area bermain dan jalan perumahan. Dengan menggunakan paving berpori air akan langsung meresap, sehingga akan mencegah adanya genangan air pada lapis permukaan paving.

Metode penelitian yang digunakan adalah menggunakan AAPA (Australian Asphalt Pavement Association) dimana dilakukan sistem Trial Eror. Campuran yang digunakan adalah 1:4, dengan menggunakan gradasi terbuka. Kuat tekan yang di rencanakan yaitu 18,00 MPa, masuk dalam kategori mutu B untuk tempat parkir mobil, pejalan kaki dan taman kota. Campuran paving menggunakan abu sekam padi sebagai reduksi semen dengan persentase $0 \%, 10 \%, 20 \%$ dan $30 \%$.

Pelaksanaan pekerjaan dimulai dari pengambilan bahan baku, pengujian material, perencanaan komposisi dan pembuatan benda uji dengan ukuran $\mathrm{P}=21 \mathrm{~cm}, \mathrm{~L}=11,5 \mathrm{~cm}$ dan $\mathrm{T}=6 \mathrm{~cm}$. Uji kuat tekan dilakukan untuk mengetahui pengaruh abu sekam sebagai bahan reduksi semen pada Paving Berpori. Nilai kuat tekan yang didapatkan akan menjadi input pada program Matlab untuk mendapatkan pemodelan Persamaan Empiris dengan ARTIFICIAL NEURAL NETWORK (ANN) sehingga didapatkan nilai kuat tekan dari berbagai komposisi penambahan bahan abu sekam. Dari hasil penelitian didapatkan persentase tertinggi dicapai pada tambahan abu sekam 30\%.
\end{abstract}

Kata kunci : Abu sekam, Artificial Neural Network (ANN), Pervious Paving, Kuat tekan, Persamaan Empiris

\section{ABSTRACT}

Pervious Paving is a construction material made from cement, water, aggregate and other materials. Pervious paving can be applied to right on sidewalks, play ground and residential roads. By using Pervious Paving, the water will absorb quickly, so it will prevent the puddles on the surface layer. AAPA (Australian Asphalt Pavement Association) is the reserach methode which we used with Trial and Eror. The mixture of ingredients is 1: 4 with the open gradation. The compressive strength designed is 18 $M P a$, which is in category B for parking car, pedestrian and city park. Paving mixture consisted of rice husk ash as cement reduction with a percentage of $0 \%, 10 \%, 20 \%$ and $30 \%$.

The work starting from the taking of raw materials, material testing, composition planning and the making of specimens with sizes $P=21 \mathrm{~cm}, L=11.5 \mathrm{~cm}$ and $T=6 \mathrm{~cm}$. The compressive strength test was conducted to determine the effect of husk ash addition. The compressive strength will be input to the Matlab program to obtain the Empirical Equation modelling with ARTIFICIAL NEURAL NETWORK (ANN). Based on the results of the study, the highest percentage was achieved in the mixture with an addition of $30 \%$ rice husk ash.

Keywords: Rice husk ash, Artificial Neural Network (ANN), Pervious Paving, Compressive strengthEmpirical Equation 


\section{PENDAHULUAN}

Pembangunan di Indonesia pada era globalisasi seperti sekarang ini sangat pesat dan merata, terutama pembangunan sarana transportasi dan pemukiman warga. Hal tersebut merupakan salah satu dampak dari meningkatnya jumlah penduduk di Indonesia. Salah satu bagian sarana dan prasarana yang penting adalah konstruksi perkerasan jalan, contohnya yaitu bata beton (concrete block) atau paving (paving block) dan paving berongga (pervious paving). Paving berongga merupakan komposisi bahan bangunan yang terbuat dari campuran semen, air dan agregat kasar atau dengan bahan campuran lainnya. Kelebihan paving berongga (pervious paving) dapat menyalurkan air ke dalam tanah, pengelolaan air hujan menjadi lebih baik, membantu menambah cadangan penyimpanan air tanah, mengurangi licin pada jalan saat hujan, serta membantu peresapan air walau perkerasan menutupi tanah. Paving berongga (pervious paving) dapat diaplikasikan untuk membuat perkerasan jalan, parkiran, taman dan trotoar. Di Indonesia masyarakat menggunakan padi sebagai bahan pokok makanannya. Sehingga otomatis padi merupakan makanan yang dipriotaskan, semakin banyak padi yang diproduksi semakin besar pula limbah dari padi tersebut yang dihasilkan. Sekam padi merupakan limbah dari hasil penggilingan padi yang belum dimanfaatkan secara optimal oleh masyarakat. Hasil pembakaran sekam padi mempunyai kandungan silika yang dominan yaitu sebesar $93 \%$. Oleh karena itu, diperlukan solusi untuk memanfaatkan limbah dari padi, salah satunya dengan memanfaatkan limbah padi atau abu sekam sebagai bahan reduksi untuk mengurangi penggunaan semen dalam pembuatan paving berongga. Penelitian ini bertujuan untuk mengetahui pengaruh Abu Sekam terhadap karakteristik pervious paving menggunakan pemodelan ANN.

\section{METODE PENELITIAN}

Penelitian menggunakan 2 (dua) metode, yaitu pengujian di Laboratorium dan pemodelan menggunakan ANN dengan menggunakan program bantu Matlab.

Pengujian yang dilaksanakan di Laboratorium untuk mencari karakteristik dari material yang digunakan dalam pervious paving dan kuat tekan dari komposisi-komposisi material yang direncanakan. Dan hasil pengujian tersebut akan dijadikan nilai input dan output pada pemodelan ANN. Menurut Schalkoff (1996) penggunaan Artificial Neural Network pertama kali diperkenalkan oleh $\mathrm{Hu}$ tahun 1964. Hu menggunakan Artificial Neural Network dalam penelitiannya dengan Metode Widrow's Adaptive Linier Networks untuk meramalkan cuaca. Dalam perkembangannya terdapat kekurangan dalam metode ini yang kemudian pada sekitar tahun 1986 diperkenalkan metode training algoritma yang baru yaitu model backpropagation oleh Rumelhart yang bisa menjawab kekurangan pada training algoritma dalam pendekatan awal Artificial Neural Network.

Langkah-langkah dalam prediksi nilai kuat tekan dengan simulasi Artificial Neural Network adalah sebagai berikut.

1) Memasukkan data input program berupa data input $\left(X_{1}-X_{4}\right)$ dan output target $\left(Y_{1}\right)$.

Data input adalah sebagai berikut.

$X_{1}$ : Persentase campuran abu sekam

$X_{2}$ : Berat Jenis kerikil

$X_{3}$ : Resapan Paving 
$X_{4}$ : Berat Volume Paving

$Y 1$ : Kuat Tekan Paving

2) Melakukan proses perhitungan atau komputasi

3) Hasil dari perhitungan tersebut berupa persamaan matematis. Persamaan matematis yang dihasilkan dari prediksi nilai kuat tekan sebagai nilai Output diatas dengan simulasi ANN adalah sebagai berikut.

$$
Y=b(2,1)+W(1,1) Z_{1}+W(2,1) Z_{2}
$$

Dimana:

$$
\begin{gathered}
Z_{1}=\frac{1}{1+e^{- \text {Zinj } 1}} \quad ; \quad Z_{2}=\frac{1}{1+e^{-Z i n j 2}} \\
Z_{\text {injl } 1}=f\left(X_{1} V(1,1)+X_{2} V(2,1)+X_{3} V(3,1)+X_{4} V(4,1)+b(1,1)\right) \ldots . \\
Z_{i n j_{2}}=f\left(X_{1} V(1,2)+X_{2} V(2,2)+X_{3} V(3,2)+X_{4} V(4,2)+b(1,2)\right) .
\end{gathered}
$$

4) Hasil perhitungan dengan Persamaan 1 di mana jika hasil dari output prediksi fungsi matematis tersebut sudah konvergen dengan output target yang dipasang sebagai pembanding, maka fungsi matematis tersebut bisa digunakan untuk prediksi nilai dimensi penampang yang optimum. Sebaliknya jika hasil dari output prediksi fungsi matematis tersebut belum konvergen dengan output target, maka dilakukan kembali proses learning atau proses iterasi untuk mendapatkan fungsi matematis yang hasilnya konvergen dengan output target yang dipasang.

Model Artificial Neural Network yang sudah didapatkan tersebut kemudian digunakan untuk menghitung prediksi nilai kuat tekan yang didapatkan dengan menggunakan persentase yang berbeda.

\section{HASIL DAN PEMBAHASAN}

A. Pengujian Laboratorium

Paving berpori dalam penelitian ini adalah material bangunan yang terdiri dari komposisi semen, abu sekam padi, agregat kasar dan air. Agregat menurut Silvia Sukirman, (2003), agregat merupakan butir-butir batu pecah, kerikil, pasir atau mineral lain, baik yang berasal dari alam maupun buatan yang berbentuk mineral padat berupa ukuran besar maupun kecil atau fragmen-fragmen. Agregat merupakan komponen utama dari struktur perkerasan jalan. Berdasarkan ASTM (American Society for Testing and Materials) C-33, agregat kasar memiliki ukuran 5-70 $\mathrm{mm}$, dengan batas bawah sebesar 4,75 mm berdasarkan saringan nomor 4 .

Campuran yang digunakan adalah perbandingan $1: 4$. Dalam penelitian ini untuk mendapatkan pemodelan ANN menggunakan persentase campuran, nilai resapan, berat volume dan berat jenis kerikil sebagai input masukan pada ANN. Sedangkan sebagai output adalah kuat tekan paving.

a. Campuran abu sekam

Campuran abu sekam padi sebagai bahan reduksi dari semen dengan menggunakan variasi campuran $0 \%$ campuran limbah abu sekam, 10\% campuran limbah abu sekam, 20\% campuran limbah abu sekam dan 30\% campuran limbah abu sekam 
b. Resapan Paving

Pengujian resapan pada paving berpori ini bertujuan untuk mengetahui karakteristik paving berpori. Pengujian ini dilakukan pada paving umur 28 hari dengan perbandingan paving 1 (semen dan abu sekam) : 4 (kerikil) dengan komposisi paving berpori yang memiliki kombinasi campuran mulai dari campuran paving persentase $0 \%$, $10 \%, 20 \%, 30 \%$ abu sekam padi.

Contoh perhitungan pengujian resapan paving berpori sebagai berikut :

Diketahui :

Berat kering paving SSD $\left(B_{j}\right)$

$=2610 \mathrm{gram}$

Berat kering paving oven $\left(B_{k}\right)$

$=2351 \mathrm{gram}$

Resapan

$$
\begin{aligned}
& =\frac{B_{j}-B_{k}}{B_{k}} \times 100 \% \\
& =\frac{2610-2351}{2351} \times 100 \%
\end{aligned}
$$

Nilai resapan rata-rata yang didapatkan ditabelkan seperti pada Tabel 1.

Tabel 1. Nilai Resapan Paving

\begin{tabular}{ll}
\hline Persentase Campuran (\%) & Resapan(\%) \\
\hline $0 \%$ & 11.45 \\
$10 \%$ & 9.69 \\
$20 \%$ & 8.36 \\
$30 \%$ & 6.75 \\
\hline
\end{tabular}

Sumber : Pengolahan Data

Pada Tabel 1 di atas, semakin banyak campuran abu sekam akan semakin menurun resapannya hal ini dikarenakan abu sekam bisa menutup pori-pori pada paving berpori, apabila persentase abu sekam yang digunakan semakin banyak maka semakin banyak pula pori-pori paving berpori yang akan tertutupi.

c. Berat Volume (SNI 03-1973-1990)

Pengujian berat volume pada paving berpori ini bertujuan untuk mengetahui karakteristik paving berpori. Pengujian ini dilakukan pada paving umur 28 hari.

Nilai berat volume rata-rata yang didapatkan ditabelkan seperti pada Tabel 2.

Tabel 2. Nilai Berat Volume Paving

\begin{tabular}{lll}
\hline $\begin{array}{c}\text { Persentase Campuran } \\
\mathbf{( \% )}\end{array}$ & $\begin{array}{l}\text { Berat } \\
\text { (gr/cm3) }\end{array}$ & volume \\
\hline $0 \%$ & 2.07 & \\
$10 \%$ & 2.1 & \\
$20 \%$ & 2.11 & \\
$30 \%$ & 2.12 & \\
\hline
\end{tabular}

Sumber : Pengolahan Data

d. Berat Jenis Kerikil

Pengujian berat jenis agregat kasar bertujuan untuk menentukan berat jenis agregat kasar untuk perhitungan volume agregat kasar yang akan dicampur pada paving berpori. Berat jenis agregat kasar yang dihitung merupakan berat jenis agregat kasar 
dalam kondisi SSD (Saturated Surface Dry) / kering permukaan. Hasil berat jenis agregat kasar didapatkan dari hasil pengujian yang telah dilakukan di Laboratorium. Dalam pengujian ini dilakukan tiga (3) kali uji dan didapatkan nilai rata-rata berat jenis kerikil adalah $2,63 \mathrm{gr} / \mathrm{cm}^{3}$

e. Kuat tekan paving

Pengujian ini bertujuan untuk mengetahui mutu dari paving berpori. Pengujian ini dilakukan pada umur 28 hari dengan meggunakan limbah abu sekam $0 \%, 10 \%, 20 \%$ dan 30\%. Pengujian dilakukan berdasarkan SNI 03-0691-1996. Nilai kuat tekan paving rata-rata yang didapatkan ditabelkan seperti pada Tabel 3.

Tabel 3. Nilai Kuat Tekan Paving

\begin{tabular}{ll}
\hline Persentase Campuran (\%) & Kuat Tekan $\left(\mathbf{k g} / \mathbf{c m}^{2}\right)$ \\
\hline $0 \%$ & 152.84 \\
$10 \%$ & 388.48 \\
$20 \%$ & 400.85 \\
$30 \%$ & 431.8 \\
\hline
\end{tabular}

Sumber : Pengolahan Data

B. Pemodelan Artificial Neural Network (ANN)

Pemodelan ANN dengan menggunakan program Matlab ini akan dihasilkan persamaan matematis untuk kemudian digunakan untuk mendapatkan persamaan empirisnya. Pada pemrograman Matlab, Bahasa pemrograman dapat terlihat pada Gambar 1.

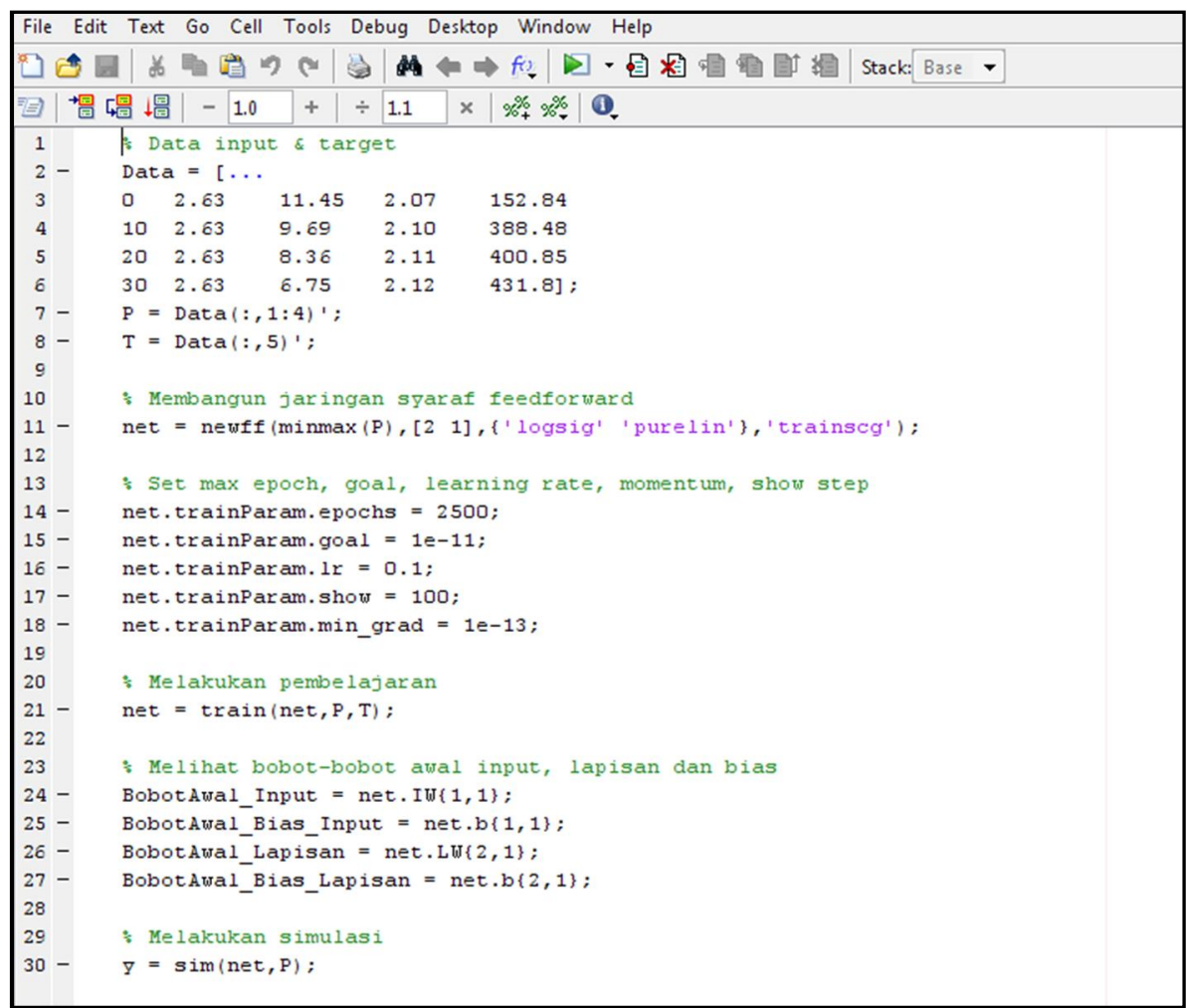

Gambar 1. Bahasa Pemrograman Data ANN di Matlab

Sumber: Data sekunder yang diolah, 2018 
1. Persamaan matematis

Persamaan matematis yang dihasilkan dari prediksi nilai kuat tekan dengan simulasi ANN dengan program Matlab, konstanta yang didapat ialah sebagai berikut.

$$
\begin{array}{cll}
V[1,1] & = & 3.5857 \\
V[1,2] & = & -0.2770 \\
V[2,1] & = & 0.1037 \\
V[2,2] & = & 5.2208 \\
V[3,1] & = & 1.2093 \\
V[3,2] & = & -2.6510 \\
V[4,1] & = & -17.3925 \\
V[4,2] & = & -31.4201 \\
b[1,1] & = & 19.3103 \\
b[1,2] & = & 80.2037 \\
W[1,1] & = & 230.4659 \\
W[2,1] & = & 114.6336 \\
b[2,1] & = & 114.8741 \\
Z_{\text {injl }}=19.3103+3.5857 X_{1}+0.1037 X_{2}+1.2093 X_{3}-17.3925 X_{4} \\
Z_{\text {inj2 }}=80.2037-0.2770 X_{1}+5.2208 X_{2}-2.6510 X_{3}-31.4201 X_{4}
\end{array}
$$

\begin{tabular}{|c|c|c|c|c|c|c|c|c|c|c|c|}
\hline \multirow[b]{2}{*}{ No } & \multicolumn{4}{|c|}{ INPUT } & \multicolumn{3}{|l|}{ OUTPUT } & \multicolumn{4}{|c|}{ Perhitungan ANN } \\
\hline & $\begin{array}{c}\text { persentas } \\
\mathrm{e}\end{array}$ & BJ & Resapan & $\begin{array}{c}\text { Berat } \\
\text { Volume }\end{array}$ & kuat tekan & $\mathrm{Znl}$ & $\mathrm{Zn} 2$ & zl & $\mathrm{Z2}$ & H-ANN & $\%$ error \\
\hline 1 & 0 & 2.63 & 11.45 & 2.07 & 152.84 & -2.57 & -1.46 & 0.07 & 0.19 & 152.84 & $0 \%$ \\
\hline 2 & 10 & 2.63 & 9.69 & 2.1 & 388.48 & 30.63 & -0.51 & 1.00 & 0.38 & 388.48 & $0 \%$ \\
\hline 3 & 20 & 2.63 & 8.36 & 2.11 & 400.85 & 64.71 & -0.06 & 1.00 & 0.48 & 400.85 & $0 \%$ \\
\hline 4 & 30 & 2.63 & 6.75 & 2.12 & 431.8 & 98.45 & 1.12 & 1.00 & 0.75 & 431.80 & $0 \%$ \\
\hline
\end{tabular}

2. Persamaan Empiris

Dengan memasukkan nilai-nilai yang didapatkan pada persamaan matematis diatas, maka didapatkan Persamaan 1 sebagai berikut :

$Y=114.8741+\left(230.4659 Z_{1}\right)+\left(114.6336 Z_{2}\right)$

Dengan:

$$
Z_{1}=\frac{1}{1+e^{- \text {Zinj1 }}} \quad ; \quad Z_{2}=\frac{1}{1+e^{- \text {Zinj } 2}}
$$

Perhitungan nilai Error yang didapat dengan menggunakan Persamaan Empiris diatas dapat dilihat pada Tabel 4

Tabel 4. Nilai Error Persamaan Empiris 


\section{KESIMPULAN}

Hasil pengujian kuat tekan tertinggi didapat pada campuran abu sekam $30 \%$ sebesar $431,80 \mathrm{~kg} / \mathrm{cm} 2$ dan kuat tekan terendah pada campuran abu sekam $0 \%$ sebesar 152,54 $\mathrm{kg} / \mathrm{cm} 2$, pengujian berat volume didapatkan nilai tertinggi pada campuran abu sekam $30 \%$ sebesar $2,12 \mathrm{gr} / \mathrm{cm} 3$ dan nilai terendah pada campuran abu sekam $0 \%$ sebesar 2,07 $\mathrm{gr} / \mathrm{cm} 3$. Dari hasil pemodelan ANN didapatkan nilai error 0\% pada tiap pengujian.

\section{DAFTAR PUSTAKA}

[1] Australian Asphalt Pavement Association (AAPA) 2004. Open Graded Asphalt

[2] Schalkoff and Robert, J. (1996), Artificial Neural Networks, McGraw-Hill, U.S.A.

[3] Standar Nasional Indonesia (SNI) 03-1973-1990, Metode Pengujian Berat Isi Beton.

[4] Standar Nasional Indonesia (SNI) SNI 03-0691-1996, Bata Beton (Paving Blok) Sukirman S, (2003).Beton Aspal Campuran Panas. 